\title{
Non-Invasive Reliable Methods to Objectify the Positive Influence of Hepatitis C Virus Treatment on Liver Stiffness
}

\author{
Florian Bert ${ }^{\mathrm{a}, \mathrm{c}}$, Jona Theodor Stahmeyer ${ }^{\mathrm{b}}$, Andra-Livia Parpalea ${ }^{\mathrm{a}}$, Siegbert Rossol ${ }^{\mathrm{a}}$
}

\begin{abstract}
Background: Chronic active hepatitis $\mathrm{C}$ virus (HCV) infection is a major public health problem and causes liver fibrosis (LF) up to liver cirrhosis (LC). LF can be estimated by non-invasive, easy handling methods. With implementation of new HCV therapies, elimination rates of $\mathrm{HCV}$ are near $100 \%$, resulting in less clinical complications and costs. The aim of our study was to evaluate the positive influence of $\mathrm{HCV}$ treatment on liver stiffness by non-invasive assessments of LF.
\end{abstract}

Methods: Sixty-two patients with HCV were treated with antiviral drug regimes. Serological fibrosis scores and ultrasound elastography (acoustic radiation force impulse and shear wave elasticity imaging (ARFI-SWEI)) were used for LF assessment on day 0 and 6 months after therapy.

Results: Antiviral treatment was successful in all cases. ARFI-SWEI measurements showed an improvement of all LF stages. Results of serological markers and scores were heterogeneous. Significant positive effects of treatment were seen for aspartate aminotransferase-to-platelet ratio index (APRI) and fibrosis-4 (FIB-4) scores, only. Further Pearson's coefficient showed moderate till very high correlations for ARFISWEI and FIB-4/APRI scores.

Conclusion: Today HCV therapy is able to cure HCV. Positive influences are improvement of LF stages. ARFI-SWEI, APRI and FIB-4 score are useful, easy handling tools to verify positive influence of $\mathrm{HCV}$ treatment on LF alone or in combination.

Keywords: Liver; Fibrosis; Elastography; Liver scores; Ultrasound

Manuscript submitted November 30, 2020, accepted January 22, 2021

Published online February 19, 2021

${ }^{a}$ Department of Internal Medicine, Krankenhaus Nordwest, Frankfurt/Main, Germany

bInstitute for Epidemiology, Social Medicine and Health Systems Research, Medical School, Hannover, Germany

${ }^{\mathrm{c} C}$ Corresponding Author: Florian Bert, Department of Internal Medicine, Krankenhaus Nordwest, Steinbacher Hohl 2-26, 60488 Frankfurt/Main, Germany. Email: bert.florian@khnw.de

doi: https://doi.org/10.14740/gr1347

\section{Introduction}

Chronic active hepatitis $\mathrm{C}$ virus (HCV) infection is a major public health problem and results in significant disease burden for individuals as well as healthcare systems. Worldwide, up to 170 million individuals are infected with $\mathrm{HCV}$, representing $2 \%$ of the total population [1]. Almost three to four million individuals per year become newly infected with $\mathrm{HCV}$, with up to $35 \%$ developing liver cirrhosis (LC) after 20 - 25 years of infection [2]. HCV is related to 500,000 deaths annually $[3,4]$.

The prevalence differs in various countries, with the highest levels in Asia, North Africa and the sub-Saharan region of Africa (i.e., Egypt 14.7\%) [5] and lower levels in the Western world (i.e., UK and Germany 0.4-0.9\%, German metropolitan areas $2.7 \%$, USA $11.1 \%$ ) [6-9].

Often, HCV infection is asymptomatic and chronic in the majority of patients (80\%); diagnosis is delayed until more advanced stages of fibrosis are present [10]. Until today, six different subtypes (genotypes (GTs)) are known [11]. A vaccination against $\mathrm{HCV}$ does not exist.

Nowadays, screening approaches have become more important since treatment of HCV has significantly improved. Evidence is accumulating that these therapies provide a costeffective means to reduce the morbidity and mortality associated with chronic $\mathrm{HCV}$ infection [3, 12]. With implementation of triple therapy, elimination rates of $\mathrm{HCV}$ increased with sustained viral response near $100 \%[1,13]$.

$\mathrm{HCV}$ infection leads to liver fibrosis (LF) up to $\mathrm{LC}$ and/or hepatocellular carcinoma (HCC) and reduced life expectancy [9, 14-18]. Successful treatment of HCV infection stops LF progression and partially reverses it $[19,20]$.

In the past, the diagnosis and follow-up of progressive LF by HCV based on histological examination used liver biopsy (LB) as "gold standard" [21]. Because this procedure has poor tolerance for many patients and is not practicable in common medical offices, non-invasive methods like serological markers and new ultrasound-based methods for daily use especially in routine care were of medical interest to evaluate liver damage [22].

The aim of our study was to find out the best non-invasive methods alone or in combination to objectify the positive influence of HCV treatment on liver stiffness for use in routine care. To our knowledge, this study is the first one with this 
Table 1. Patients Characteristics and Therapy Results

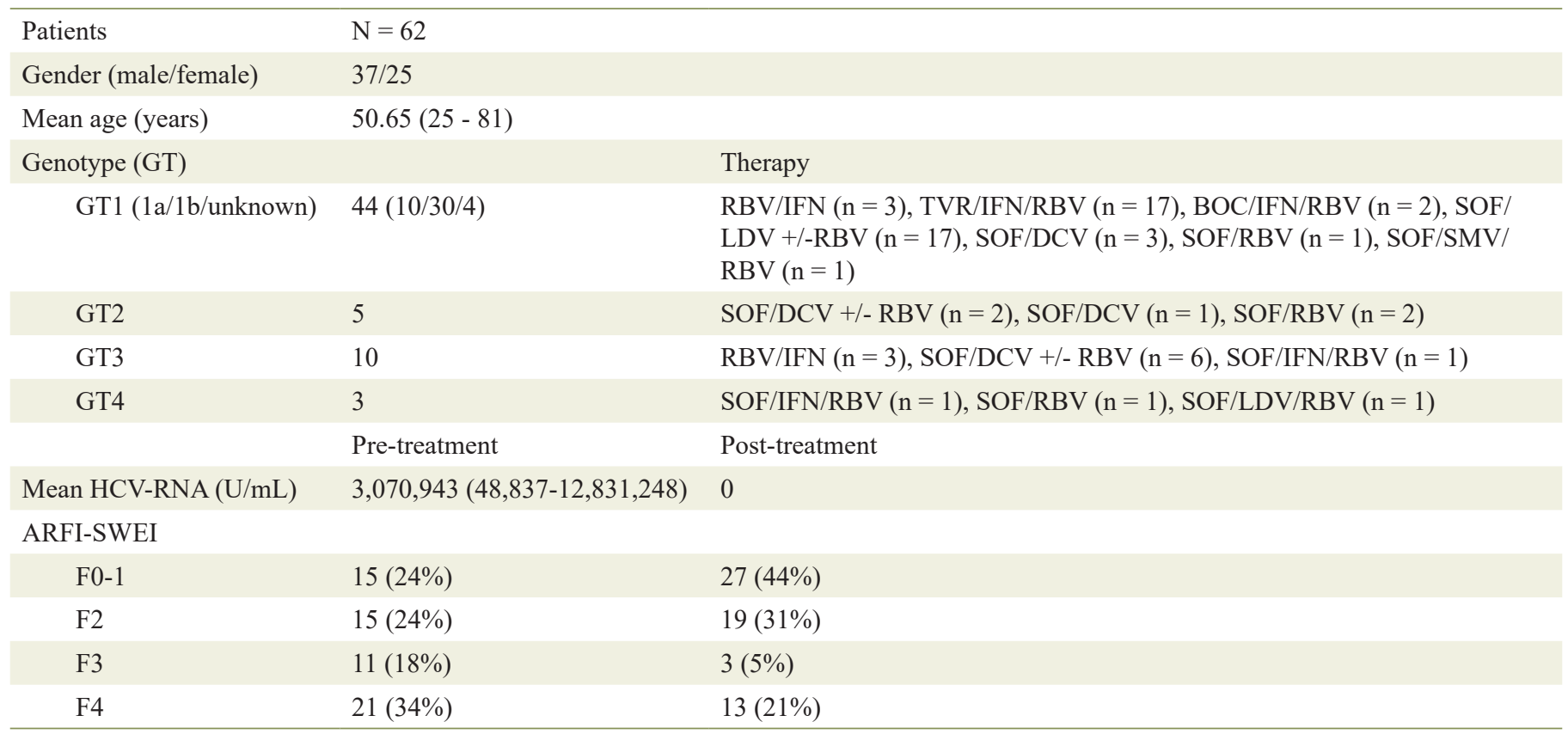

ARFI-SWEI: acoustic radiation force impulse and shear wave elasticity imaging; IFN: pegylated Interferon; RBV: ribavirin; TVR: telaprevir; BOC: boceprevir; SOF: sofosbuvir; SMV: simeprevir; DCV: daclatasvir; LDV: ledipasvir.

kind of concept and ambition. In this context, we compared chronological acquired on- and off-treatment patient parameters using acoustic radiation force impulse and shear wave elasticity imaging (ARFI-SWEI), and serological scores (aspartate aminotransferase/alanine aminotransferease (AST/ ALT) ratio, fibrosis-4 (FIB-4) index, Pohl's score and ASTto-platelet ratio index (APRI)). Especially ARFI-SWEI as the only ultrasound-based method used in this context will be correlated to serological scores.

\section{Materials and Methods}

\section{Patients}

Between 2012 until 2016, 62 of patients with documented $\mathrm{HCV}$ and scheduled for antiviral therapy were included in this prospective, observational study. The patients were generated as outpatient of the medical Health Center of the Krankenhaus Nordwest in Frankfurt (Main). In the above period, out of patients of nearly 250 treated on HCV, 62 patients were interested in participating only.

Criteria for selection of all patients who took part in this study were positive antibodies for $\mathrm{HCV}$ and verifiable virus amount over at least 6 months as evidence for chronic active infection, only. Patients were included independent of actual or in case of prior antiviral HCV therapy. HCV genotypes were tested for all patients. The study was conducted in compliance with the Declaration of Helsinki. The institutional review board approved the study and the patients were informed of the study procedure.

\section{HCV-RNA and genotype}

For all participants' quantification of HCV-RNA using the real-time PCR-based COBAS TaqMan 48 HCV High Pure System (Roche Diagnostics, Mannheim, Germany) and genotyping by Siemens Versant HCV genotype 2.0 assay (Siemens Healthcare $\mathrm{GmbH}$, Erlangen, Germany) were performed. Success of therapy was estimated 6 months after therapy by HCV quantification.

\section{Antiviral therapy}

The treatment of the different genotypes regarding kind and duration of therapy was adapted to patients medical condition, fibrosis status of the liver and dependent of treatments availability: the combination of pegylated interferon (IFN) with nucleoside analog ribavirin (RBV) was available since 2002, directly acting antivirals (DAAs) like protease inhibitors telaprevir (TVR) and boceprevir (BOC) since 2011, polymerase inhibitor sofosbuvir (SOF), protease inhibitor simeprevir (SMV), NSA5A-inhibitors daclatasvir (DCV) and ledipasvir (LDV) since 2014 [13, 23-25].

The patient characteristics and therapy results are shown in Table 1.

\section{Serological markers}

Additional blood samples of the participants were taken: AST and ALT as well as the platelet count. These parameters were 


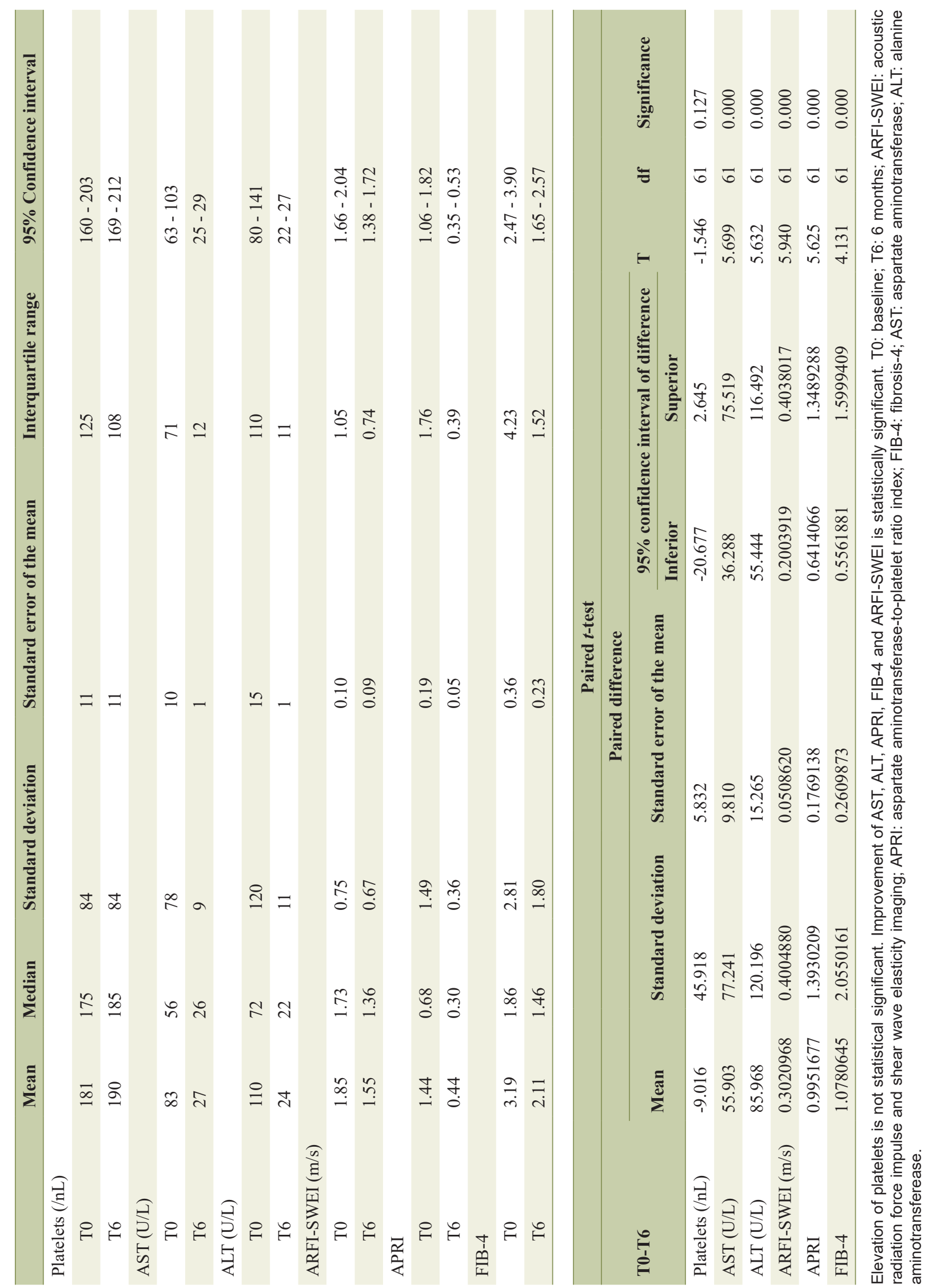


used for estimating liver damage or LF by scores (Table 2). They were checked on day 0 (pre-treatment) and 6 months after therapy (post-treatment).

LB and its histologic analyses were not the aim of this study, neither the estimation of surveillance nor pharmacologic side effects of therapy.

\section{Determination of LF}

For estimating liver failure and LF, we used the platelet count and four established serological scores (AST/ALT ratio, APRI, FIB-4 index and Pohl's score) as well as liver B-mode ultrasound in combination with liver stiffness measurement (ARFISWEI).

Results of these methods that were predictive for various fibrosis stages were correlated to the histological classification of METAVIR (F0-4) based on published literature (METAVIR, LF stages F0-1: F0: no fibrosis; F1: portal fibrosis without septa; F2: few septa; F3: numerous septa without cirrhosis; F4: cirrhosis) [25-27].

\section{AST/ALT ratio}

The AST/ALT ratio or De-Ritis-Quotient used in estimation of various liver diseases for more than 30 years describes the relation of AST and ALT. The range of the dimensionless ratio is between 0.6 and 0.8 . The area under the receiver-operating characteristic curve (AUROC) for LF $\geq \mathrm{F} 3$ varies between 0.68 and 0.78 . In daily routine, AST/ALT ratio $<1$ reflects slightly and ratio $>1$ reflects severe liver failure (i.e., cirrhosis) $[28,29]$.

\section{$A P R I$}

This index was developed by Wai et al [30]. APRI was proposed as an alternative to biopsy in patients with chronic $\mathrm{HCV}$ infection and it is calculated as (AST/upper limit of normal range $) /$ platelet count $\left(10^{9} / \mathrm{L}\right) \times 100$. A large meta-analysis suggests that APRI can identify HCV-related fibrosis with a moderate degree of accuracy and AUROC scores for the diagnosis of significant fibrosis ( $\geq$ F2) between 0.77 and 0.83 . Values $>$ 1.5 signify LF certainly values below 0.5 exclude LF. In case of LC, threshold value is $>2$, and LC is excluded by $<1$ [31].

\section{FIB-4 index}

This index combines the liver enzymes AST/ALT, platelet count and age into the formula: age (years) $\times$ AST $(\mathrm{U} / \mathrm{L}) /($ platelets $\left(10^{9} / \mathrm{L}\right) \times$ ALT $\left.(\mathrm{U} / \mathrm{L})\right)$. The FIB-4 index was specifically developed as an alternative to biopsy in patients with human immunodeficiency virus (HIV) and chronic HCV infection coinfection [32]. The AUROC of the FIB-4 index was 0.765 for differentiation between Ishak stage $0-3$ and 4-6. At a cutoff of $<1.45$ in the validation set, the negative predictive value to ex- clude advanced fibrosis (stage 4-6) was $90 \%$ with a sensitivity of $70 \%$. A cutoff of $>3.25$ had a positive predictive value of $65 \%$ and a specificity of $97 \%$. Using these cutoffs, $87 \%$ of patients with FIB-4 values outside 1.45 - 3.25 would be correctly classified, and LB could be avoided in $71 \%$ of cases.

\section{Pohl's score}

Pohl et al used AST/ALT ratio and platelet counts as predictors of degree of fibrosis in HCV infection. These parameters are correlated significantly with disease stage $(r=0.190, P=0.006$ and $\mathrm{r}=-0.543, \mathrm{P} \leq 0.001)$. For patients without history of alcohol abuse, the correlation between disease stage, AST/ALT ratio and platelet counts was $\mathrm{r}=0.297, \mathrm{P} \leq 0.001$ and $\mathrm{r}=0.560$, $\mathrm{P} \leq 0.001$, respectively. In these patients, AST/ALT ratio $\geq 1$ in combination with a platelet count of $<150,000 / \mathrm{mm}^{3}$ could identify patients with severe fibrosis or cirrhosis (F3 and F4) with a positive predictive value of $93.1 \%$. Sensitivity, specificity and negative predictive value were $41.2 \%, 99.1 \%$ and $85.0 \%$, respectively. In patients with ALT/AST ratio of $<1$ or platelet counts of $>150,000 / \mathrm{mm}^{3}$, these laboratory parameters cannot predict LF stage [33].

\section{Native ultrasound scan and ARFI-SWEI}

Two physicians performed native ultrasound scan and elastographic measurements independently with an ultrasound unit by Siemens AG (Germany), Acuson S 2000, which included the Virtual Touch Tissue Quantification $\left(\mathrm{VTQ}^{\circledR}\right)$ Software for ARFI-SWEI technology. The ultrasound unit contains tissue harmonic imaging (THI), which resolves the problems related to ultrasound in technically difficult patients by providing a marked improvement in image quality. We used a 4C1 curved transducer with a frequency of $4.5 \mathrm{MHz}$ and mechanical index of $1.1-1.2$.

ARFI-SWEI technology, a point shear wave elastography, is a real-time dual display imaging mode and allows a quantitative assessment of tissue stiffness, through measurement of shear wave velocity (SWV). The technical principle of ARFISWEI is established and well described by other authors [34].

To optimize the results, we standardized our ARFI-SWEI measurement. We did the examination in the morning and the patients were without food intake and fasting $>3 \mathrm{~h}$. The patient was arranged in dorsal decubitus position, with the right arm under his head (maximum abduction). We made ARFI-SWEI measurement at the level of the right liver lobe segment VII/ VIII at a depth between 3.5 and $8.0 \mathrm{~cm}$, while the patients were asked to stop breathing for a moment. Ten valid measurements were performed in every patient, and the ratio between validated and total measurements as a median value was calculated.

Only procedures with a success rate of at least $60 \%$, and with the interquartile range of all validated measurements $<$ $30 \%$ of the median value, were considered reliable. We compared the results of ARFI-SWEI measurements with published SWV cutoff values that were predictive for each fibrosis stage correlated to the histological classification of METAVIR (F0- 
Table 3. Correlation of Metric Values: ARFI-SWEI, APRI Score and FIB-4 Index $(N=62)$

\begin{tabular}{|c|c|c|c|c|c|c|}
\hline \multirow{2}{*}{ Pearson (metric) } & \multicolumn{3}{|c|}{ Baseline } & \multicolumn{3}{|c|}{6 months } \\
\hline & ARFI-SWEI & APRI & FIB-4 & ARFI-SWEI & APRI & FIB-4 \\
\hline \multicolumn{7}{|l|}{ ARFI-SWEI } \\
\hline \multicolumn{7}{|l|}{ APRI } \\
\hline Correlation & $0.398 * *$ & 1 & $0.798 * *$ & $0.432 * *$ & 1 & $0.922 * *$ \\
\hline
\end{tabular}

${ }^{* *}$ Correlation significance 0.01 . ARFI-SWEI: acoustic radiation force impulse and shear wave elasticity imaging; APRI: aspartate aminotransferaseto-platelet ratio index; FIB-4: fibrosis-4.

4): $\mathrm{F} 0-1<1.24 \mathrm{~m} / \mathrm{s}, \mathrm{F} 2 \geq 1.25 \mathrm{~m} / \mathrm{s}, \mathrm{F} 3 \geq 1.60 \mathrm{~m} / \mathrm{s}$ and $\mathrm{F} 4 \geq$ $2.00 \mathrm{~m} / \mathrm{s}$. A distinguishing between F0 and F1 and conclusions about the activity of (necro-)inflammation in the liver tissue is impossible for ARFI-SWEI and can be estimated by histology only.

ARFI-SWEI was done pre- and 6 months post-treatment.

\section{Statistical analyses}

Clinical and laboratory characteristics of patients were expressed as mean and standard deviation (SD) or percentages, as appropriate. Pre-post differences were analyzed applying the paired $t$-test or Wilcoxon rank-sum test depending on the type of variable. A significance level of $\mathrm{P} \leq 0.05$ was used. Correlation of fibrosis scores was assessed using Pearson cor- relation. Interpretation of the correlation coefficient $(\mathrm{r})$ was: $\mathrm{r} \leq 0.35 \mathrm{low} / \mathrm{weak}$ correlation, $0.36-0.67$ modest/moderate correlation, $0.68-1.0$ strong/high correlation and $\geq 0.9$ very high correlation [35].

For statistical analysis, we used Microsoft Excel (Microsoft Corporation, Redmond, Washington, USA) and SPSS 20.
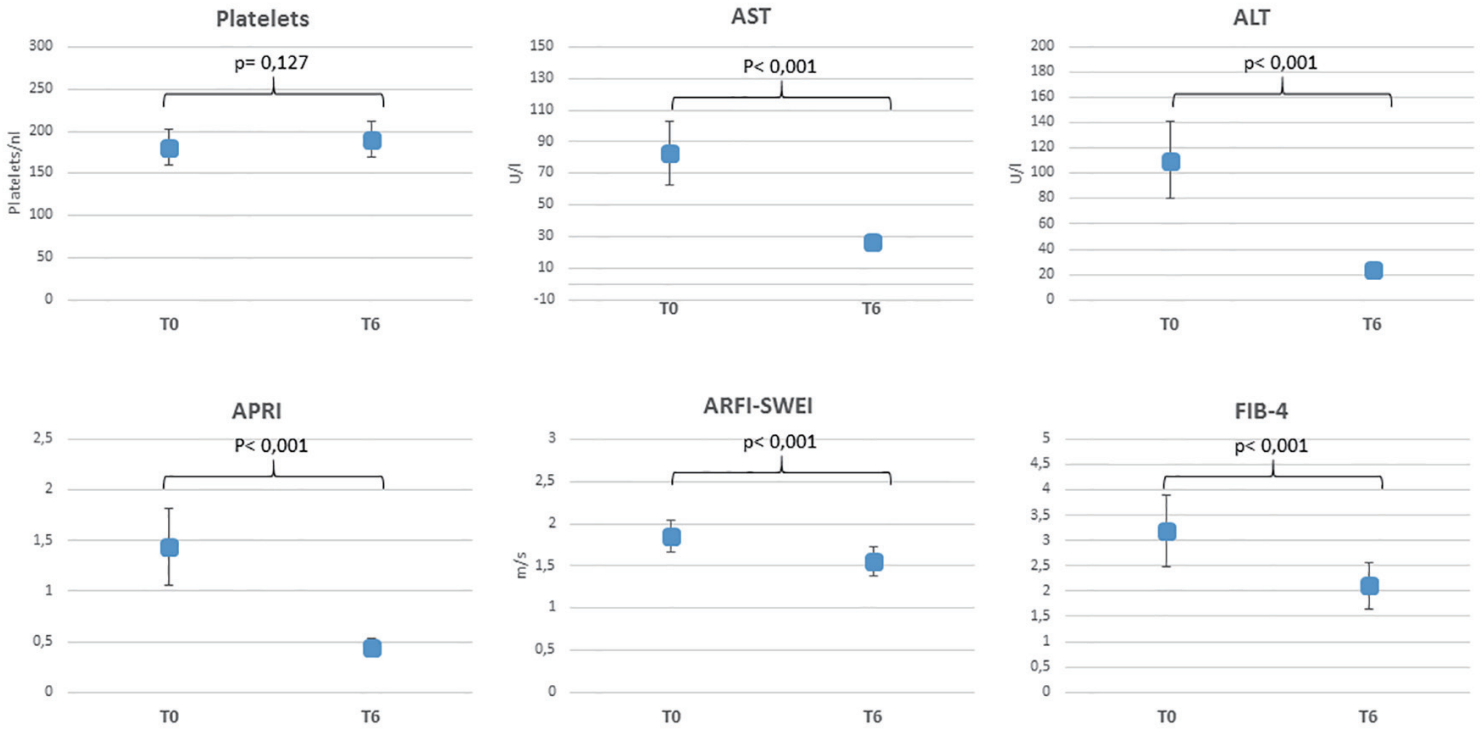

TO: Baseline T6: 6 months

Figure 1. Mean values pre- and post-treatment. ARFI-SWEI: acoustic radiation force impulse and shear wave elasticity imaging; APRI: aspartate aminotransferase-to-platelet ratio index; FIB-4: fibrosis-4; AST: aspartate aminotransferase; ALT: alanine aminotransferease. 
lowed by GT3 $(n=10)$, GT2 $(n=5)$ and GT4 $(n=3)$. The allocation of drug regimens for the different genotypes is listed in Table 1.

The mean viral load pre-treatment was $3,070,943 \mathrm{U} / \mathrm{mL}$ (48,837 - 12,831,248 U/mL); viral load 6 months post-treatment was not detectable in all participants. Thus, treatment was successful for each patient.

\section{Liver elastography (ARFI-SWEI)}

As shown in Table 1, 21 of 62 patients (34\%) presented elastography results corresponding to LF F4 before initiating antiviral treatment; 6 months post-treatment, eight of these 21 $(38 \%)$ patients received an improvement of liver stiffness to F2 $(n=5)$ or F3 $(n=3)$, while 13 patients still showed F4. All patients with initial fibrosis F3 (11) changed to fibrosis F1 $(n=3)$ or F2 $(n=8)$. Ten patients with initial F2 improved to fibrosis grade F0-1 and further five patients kept F2. Fifteen patients had fibrosis F0-1 pre-treatment and 14 of them were also 6 months after therapy, while one female patient changed to F2.

In total, the part of patients with $\mathrm{F} 0-1$ raised from $24 \%$ (n $=15)$ to $44 \%(\mathrm{n}=27) 6$ months after therapy, patients with $\mathrm{F} 2$ from $24 \%(n=15)$ to $31 \%(n=19)$ and the part of participants with LF F3 and F4 declined from 18\% $(\mathrm{n}=11)$ to $5 \%(\mathrm{n}=3)$ and from $34 \%(\mathrm{n}=21)$ to $21 \%(\mathrm{n}=13)$, respectively.

Of all 62 participants, 29 (46.8\%) got an improvement of LF 6 months after HCV therapy and $32(51.6 \%)$ had no alteration of LF, while one patient got degradation. The mean value of ARFI declined from $1.85 \mathrm{~m} / \mathrm{s}$ (F3) to $1.55 \mathrm{~m} / \mathrm{s}$ (F2) (Fig. 1).

\section{Platelet count and liver enzymes}

The platelet count in all four elastographic groups had big variability pre- and post-treatment and mean values differed insignificantly (Table 2, Fig. 1).

On the other hand, values for transaminases AST and ALT changed significant: 41 of $62(66.12 \%)$ patients had elevated AST and ALT values, additional nine (14.52\%) had elevated ALT, only. Six months after HCV treatment, AST and ALT values normalized in all participants except four patients with slightly elevated values over the normal range.

\section{Fibrosis scores}

For estimation of LF, we used four scores, which were generated out of the variable's platelet count, AST, ALT and their standard values gender adapted.

\section{AST/ALT ratio}

AST/ALT ratio had less validity to predict LF (results not listed in Table 2). Its usage is dedicated for elevated AST and ALT values, only and has no significance in context of normal liver enzymes values. Six months after therapy, liver enzymes were in normal range for nearly all patients and the ratio could not be used, while several patients still had elastographic signs of LF.

\section{Pohl's score}

The results of this score were heterogeneous. In total Pohl's score indicates a failure of LF post-treatment, which is contradictory to the other results (not listed in Table 2).

Twenty-eight of all patients had no hints of a relevant fibrosis by Pohl's score pre-treatment, but post-treatment 13 patients only. No statements regarding fibrosis were feasible in 22 participants pre-treatment and in 35 post-treatment. Pohl's score correlating to advanced fibrosis could be seen in 12 patients before and in 14 patients 6 months after therapy.

In total eight patients had a verifiable improvement, 28 had no changing and 26 had deterioration of fibrosis respecting this score.

\section{APRI}

Mean APRI value pre-treatment was 1.44 and improved significantly 6 months post-treatment $(0.44, \mathrm{P}<0.001)$ (Fig. 1). The part of patients with APRI scores $<0.5$ increased from $37 \%(\mathrm{n}=23)$ before treatment to $71 \%(\mathrm{n}=44)$ after therapy. On the other hand, parts of patients with scores between 0.5 1.5 and $>1.5$ were falling $(32 \%(n=20)$ vs. $29 \%(n=18)$ and $31 \%(\mathrm{n}=19)$ vs. $3 \%(\mathrm{n}=2))$. In $51.6 \%$ of the cases $(\mathrm{n}=32)$, scores were improving, in $46.8 \%(\mathrm{n}=29)$ no changes could be observed and in only one case (1.6\%) the scores deteriorated, revealed by APRI classes.

\section{FIB-4}

Mean values of FIB-4 pre- and post-treatment decreased significantly, as a hint of overall improvement of LF (3.19 vs. 2.11, P $<0.001$ ) (Fig. 1). The part of patients with FIB-4 score $<1.45$ as a negative predictive value of $90 \%$ for advanced fibrosis rose after therapy from $32 \%(\mathrm{n}=20)$ pre-treatment up to $47 \%(\mathrm{n}=29)$ post-treatment. On the other hand, the part of patients with score $>3.25$ decreased after therapy from $37 \%$ (n $=23)$ to $15 \%(\mathrm{n}=9)$ and the portion of patients with scores of $1.45-3.25$ climbed up from $31 \%(n=19)$ to $39 \%(n=24)$. In total, $38.7 \%(\mathrm{n}=24)$ of all patients $(\mathrm{n}=62)$ had an improvement, $56.5 \%(\mathrm{n}=35)$ had no changing and $4.8 \%(\mathrm{n}=3)$ had a deterioration of the score.

\section{Correlation of scores}

Pearsońs correlation of metric values for ARFI-SWEI, APRI and FIB-4

Table 3 shows Pearson's coefficient demonstrating a moder- 
ate correlation for ARFI-SWEI and APRI/FIB-4 scores and a high correlation for APRI and FIB-4 scores pre-treatment. Post-treatment the correlation coefficient rises up to 0.922 as a hint for very high correlation, while the correlation between ARFI-SWEI and APRI/FIB-4 scores is still moderate. But it seems that a linear correlation can be stated.

\section{Discussion}

Germany's HCV prevalence is estimated near $0.9 \%$, and in metropolitan up to $2.7 \%$ [9]. The majority of patients acquired genotype 1 or 3 hepatitis C, like our results confirm [36]. Goals of treating $\mathrm{HCV}$ are eradicating the virus (SVR) and reducing morbidity and mortality. Today SVR of therapy is near $100 \%$. By treating HCV, viral-induced inflammation of liver and progress of fibrosis are stopped resulting in improvement of liver function [19]. Patients with SVR subsequently develop fewer adverse endpoints such as cirrhosis, decompensation and hepatocellular carcinoma (HCC), irrespective of the antiviral combination used. Current German guidelines recommend interferon-free regimens as first-choice treatment [37]. Further, evidence is accumulating that DAA therapies provide a cost-effective means to reduce the morbidity and mortality associated with chronic infection with HCV [20]. In our study, all patients achieved SVR of 100\% 6 months after therapy. But studies show in patients with LF F3 and F4/LC higher risk of new HCC occurrence in spite of successful treatment; therefore regular follow-ups every 6 months are obligatory [38].

The aim of our study was to objectify the positive influence of HCV treatment on liver stiffness using non-invasive methods using serological parameters like platelet count, AST, ALT as well as four different scores (APRI, FIB-4, AST/ALT ratio and Pohl's score), and ARFI-SWEI for evaluating LF. Literature search showed limited studies comparing the efficacy of these parameters head to head.

Ultrasound is a simple and non-invasive imaging modality available worldwide. B-mode imaging allows broad applications for patients to detect chronic liver diseases and focal hepatic lesions. Since over one-decade ARFI-SWEI is used for non-invasive assessment of LF and has been correlated to histologic examination extensively in patients with chronic HCV infection. Cutoffs of $1.21-1.34 \mathrm{~m} / \mathrm{s}$ predict significant fibrosis $(F \geq 2$, AUROC $0.85-0.89)$ and virtual touch quantification cutoffs between 1.55 and $2 \mathrm{~m} / \mathrm{s}$ (AUROC 0.89 - 0.93) cirrhosis; the method can be influenced by some factors like fasting and operator bias as well as anthropometric characteristics (i.e., high body mass index (BMI) or gender) [34]. By standardizing the procedures, these influences could be minimized.

As our results show, successful treatment of $\mathrm{HCV}$ infection leads to an improvement of ARFI-SWEI results in our patients in $84 \%$ of the cases, better than described in other studies with improvement of liver stiffness in just $57 \%$ of $\mathrm{HCV}$-infected patients after interferon-free treatment in comparable setting [39]. It seems still controversial, whether and to what amount fibrosis and cirrhosis are reversible in patients with successfully treated HCV, and if improvement of liver stiffness measurement may be rather due to reduced necroinflammation and less extent to regression of cirrhosis.

Reduced platelet counts indicate high-grade LF (F3) or LC. Ikarashi et al found optimal cutoff values for platelet count for diagnosis of LC in HCV patients of $12.7 \times 10^{4} / \mu \mathrm{L}$ with sensitivity of $57.8 \%$ and specificity of $88.2 \%$ (AUC, 0.863 ) [40]. In our study, platelet counts could not specify F3 fibrosis or LC. A statistical significance pre- and post-treatment was not available.

Elevation of AST and/or ALT is not seen in patients with chronic HCV infection regularly [10]. In our study, $65 \%$ of the participants had elevated AST and ALT values pre-treatment independent of fibrosis stage by ARFI-SWEI. After therapy, $95 \%$ reached normal values (statistically significant). It seems that these parameters had no explanatory power in predicting LF, a fact described by Karin et al equally [40]. It can be concluded that virological and biochemical responses alone did not reflect effects of the treatment on fibrosis grade.

AST/ALT or De-Ritis ratio was developed 50 years ago $[41,42]$ and it was stated that in HCV elevated AST/ALT ratio is predictive of long-term complications like fibrosis and cirrhosis [29]. In context to our results, this interpretation is far too simplistic and the ratio is not sufficient to predict advanced liver disease. These findings are congruent to those of Eminler et al, who found no significant relationship between degree of $\mathrm{LF}$ and the AST/ALT ratio, and we think that AST/ALT ratio is not useful in estimating the fibrosis stage in HCV patients [43].

Pohl's score seemed to be the less useable score tested. Our results did not show any correlation to LF stages or were able to reflect a correlation to HCV treatment and positive influence on LF as described by Thandassery also [44].

APRI score includes the parameters AST and platelet count. According to various studies, APRI could be the best simple indirect non-invasive score in estimating LF in context with HCV treatment like our study demonstrates. We saw improvement of APRI score in $90 \%$ of the patients. Similar findings were made by Chen et al with improved APRI scores after therapy [45].

Equally findings were found using FIB-4 score. HCV therapy led to improvement of FIB-4 score in over $74 \%$ of the cases and seemed that FIB-4 score is a reliable tool in detecting LF. A large observational cohort study perceived that FIB-4 is good in differentiating various stages of LF in patients with chronic HCV infection, more than APRI [46]. The test can be influenced by age [47]. McPherson et al describe high accuracy of FIB-4 score for advanced fibrosis in patients with liver diseases aged $>35$ years and unacceptable low specificity for advanced fibrosis in patients aged $\geq 65$ years, resulting in a high false positive rate. We did not correlate our results with patient's age. The mean age of the participants was 51 years and part of patients over 65 years were less for reliable statements. At last it must be stated that both, APRI and FIB-4 scores, were useful in detecting LF like the findings show [22].

Some studies correlated APRI or FIB-4 scores with ARFISWEI in HCV patients and demonstrated high correlation of these scores with ARFI-SWEI. But it seems that ARFI-SWEI is more accurate in this context $[48,49]$. We correlated APRI score, FIB-4 index and ARFI and saw best correlation of metric values (Pearson's coefficient) of APRI score and FIB-4 index more than one of the scores versus ARFI-SWEI. 
A partial correlation for gender as covariate in context with metric variables made no difference in results and a correlation in regard to age with the patients count is too less.

In conclusion, screening for $\mathrm{HCV}$ is more and more necessary because antiviral HCV therapy since 2011 and especially since implementation of DAA 2014 is successful to cure chronic HCV infection with prevention of progressive liver failure and cancer. Our study correlates non-invasive assessment of LF in patients with HCV pre- and post-therapeutic and demonstrates the positive influence of antiviral HCV treatment on LF in different stages by normalization or improvement.

As our results show APRI score and FIB-4 index are easy handling methods with best validity in estimation of LF, more than ARFI-SWEI. But the combination of ARFI-SWEI and these scores is a reliable tool with high validity for LF assessment.

\section{Acknowledgments}

None to declare.

\section{Financial Disclosure}

The authors have no financial disclosure to report.

\section{Conflict of Interest}

The authors declare that they have no conflict of interest.

\section{Informed Consent}

Informed consent was obtained.

\section{Author Contributions}

FB contributed to the concept and design of study; JTS contributed to statistical analysis; ALP contributed to data acquisition; SR analyzed the data and drafted the manuscript. All authors critically revised the manuscript, approved the final version to be published, and agree to be accountable for all aspects of the work.

\section{Data Availability}

The authors declare that data supporting the findings of this study are available within the article.

\section{References}

1. Orkin C, Leach E, Flanagan S, Wallis E, Ruf M, Foster GR, Tong CY. High prevalence of hepatitis C (HCV) in the emergency department (ED) of a London hospital: should we be screening for HCV in ED attendees? Epidemiol Infect. 2015;143(13):2837-2840.

2. El Khoury AC, Wallace C, Klimack WK, Razavi H. Economic burden of hepatitis $\mathrm{C}$-associated diseases: Europe, Asia Pacific, and the Americas. J Med Econ. 2012;15(5):887-896.

3. Heidrich B, Cetindere A, Beyaz M, Stahmeyer JT, Basaran MM, Braynis B, Raupach R, et al. High prevalence of hepatitis markers in immigrant populations: a prospective screening approach in a real-world setting. Eur J Gastroenterol Hepatol. 2014;26(10):1090-1097.

4. Lozano R, Naghavi M, Foreman K, Lim S, Shibuya K, Aboyans V, Abraham J, et al. Global and regional mortality from 235 causes of death for 20 age groups in 1990 and 2010: a systematic analysis for the Global Burden of Disease Study 2010. Lancet. 2012;380(9859):2095-2128.

5. Mohamoud YA, Mumtaz GR, Riome S, Miller D, AbuRaddad LJ. The epidemiology of hepatitis $\mathrm{C}$ virus in Egypt: a systematic review and data synthesis. BMC Infect Dis. 2013;13:288.

6. Smith BD, Morgan RL, Beckett GA, Falck-Ytter Y, Holtzman D, Ward JW. Hepatitis C virus testing of persons born during 1945-1965: recommendations from the Centers for Disease Control and Prevention. Ann Intern Med. 2012;157(11):817-822.

7. Galbraith JW, Franco RA, Donnelly JP, Rodgers JB, Morgan JM, Viles AF, Overton ET, et al. Unrecognized chronic hepatitis $\mathrm{C}$ virus infection among baby boomers in the emergency department. Hepatology. 2015;61(3):776-782.

8. Cornberg M, Razavi HA, Alberti A, Bernasconi E, Buti M, Cooper C, Dalgard O, et al. A systematic review of hepatitis $\mathrm{C}$ virus epidemiology in Europe, Canada and Israel. Liver Int. 2011;31(Suppl 2):30-60.

9. Bert F, Rindermann A, Abdelfattah MA, Stahmeyer JT, Rossol S. High prevalence of chronic hepatitis B and C virus infection in a population of a German metropolitan area: a prospective survey including 10215 patients of an interdisciplinary emergency unit. Eur J Gastroenterol Hepatol. 2016;28(11):1246-1252.

10. Mauss S, Jablonowski H, Huppe D. [Even with normal transaminases the liver can be infected with $\mathrm{HBV}$ or HCV]. MMW Fortschr Med. 2010;152(17):62-64.

11. Manos MM, Shvachko VA, Murphy RC, Arduino JM, Shire NJ. Distribution of hepatitis C virus genotypes in a diverse US integrated health care population. J Med Virol. 2012;84(11):1744-1750.

12. Hahne SJ, Veldhuijzen IK, Wiessing L, Lim TA, Salminen M, Laar M. Infection with hepatitis $B$ and $C$ virus in Europe: a systematic review of prevalence and costeffectiveness of screening. BMC Infect Dis. 2013;13:181.

13. European Association for the Study of the Liver. EASL Recommendations on Treatment of Hepatitis C 2016. J Hepatol. 2017;66(1):153-194.

14. Lencioni R, Kudo M, Ye SL, Bronowicki JP, Chen XP, Dagher L, Furuse J, et al. GIDEON (Global Investigation of therapeutic DEcisions in hepatocellular carcinoma and Of its treatment with sorafeNib): second interim analysis. Int J Clin Pract. 2014;68(5):609-617. 
15. European Association for Study of Liver. Asociacion Latinoamericana para el Estudio del Higado. EASLALEH clinical practice guidelines: non-invasive tests for evaluation of liver disease severity and prognosis. J Hepatol. 2015;63(1):237-264.

16. Silberstein E, Ulitzky L, Lima LA, Cehan N, TeixeiraCarvalho A, Roingeard P, Taylor DR. HCV-mediated apoptosis of hepatocytes in culture and viral pathogenesis. PLoS One. 2016;11(6):e0155708.

17. Gines P, Quintero E, Arroyo V, Teres J, Bruguera M, Rimola A, Caballeria J, et al. Compensated cirrhosis: natural history and prognostic factors. Hepatology. 1987;7(1):122-128.

18. Balogh J, Victor D, 3rd, Asham EH, Burroughs SG, Boktour M, Saharia A, Li X, et al. Hepatocellular carcinoma: a review. J Hepatocell Carcinoma. 2016;3:41-53.

19. Elsharkawy A, Alem SA, Fouad R, El Raziky M, El Akel W, Abdo M, Tantawi O, et al. Changes in liver stiffness measurements and fibrosis scores following sofosbuvir based treatment regimens without interferon. J Gastroenterol Hepatol. 2017;32(9):1624-1630.

20. Stahmeyer JT, Rossol S, Bert F, Boker KH, Bruch HR, Eisenbach C, Link R, et al. Outcomes and costs of treating hepatitis $\mathrm{C}$ patients in the era of first generation protease inhibitors - results from the PAN study. PLoS One. 2016;11(7):e0159976.

21. Tannapfel A, Dienes HP, Lohse AW. The indications for liver biopsy. Dtsch Arztebl Int. 2012;109(27-28):477483.

22. Abdollahi M, Pouri A, Ghojazadeh M, Estakhri R, Somi M. Non-invasive serum fibrosis markers: A study in chronic hepatitis. Bioimpacts. 2015;5(1):17-23.

23. Cornberg M, Wedemeyer H, Manns MP. Treatment of chronic hepatitis $\mathrm{C}$ with PEGylated interferon and ribavirin. Curr Gastroenterol Rep. 2002;4(1):23-30.

24. Vermehren J, Sarrazin C. New HCV therapies on the horizon. Clin Microbiol Infect. 2011;17(2):122-134.

25. Gane EJ, Stedman CA, Hyland RH, Ding X, Svarovskaia E, Symonds WT, Hindes RG, et al. Nucleotide polymerase inhibitor sofosbuvir plus ribavirin for hepatitis C. N Engl J Med. 2013;368(1):34-44.

26. Bedossa P, Poynard T. An algorithm for the grading of activity in chronic hepatitis C. The METAVIR Cooperative Study Group. Hepatology. 1996;24(2):289-293.

27. Bert F, Stahmeyer JT, Rossol S. Ultrasound Elastography Used for Preventive Non-Invasive Screening in Early Detection of Liver Fibrosis. J Clin Med Res. 2016;8(9):650655.

28. Williams AL, Hoofnagle JH. Ratio of serum aspartate to alanine aminotransferase in chronic hepatitis. Relationship to cirrhosis. Gastroenterology. 1988;95(3):734-739.

29. Botros M, Sikaris KA. The de ritis ratio: the test of time. Clin Biochem Rev. 2013;34(3):117-130.

30. Wai CT, Greenson JK, Fontana RJ, Kalbfleisch JD, Marrero JA, Conjeevaram HS, Lok AS. A simple noninvasive index can predict both significant fibrosis and cirrhosis in patients with chronic hepatitis C. Hepatology. 2003;38(2):518-526.

31. Lin ZH, Xin YN, Dong QJ, Wang Q, Jiang XJ, Zhan SH,
Sun Y, et al. Performance of the aspartate aminotransferase-to-platelet ratio index for the staging of hepatitis C-related fibrosis: an updated meta-analysis. Hepatology. 2011;53(3):726-736.

32. Sterling RK, Lissen E, Clumeck N, Sola R, Correa MC, Montaner J, M SS, et al. Development of a simple noninvasive index to predict significant fibrosis in patients with HIV/HCV coinfection. Hepatology. 2006;43(6):13171325.

33. Pohl A, Behling C, Oliver D, Kilani M, Monson P, Hassanein T. Serum aminotransferase levels and platelet counts as predictors of degree of fibrosis in chronic hepatitis $\mathrm{C}$ virus infection. Am J Gastroenterol. 2001;96(11):31423146.

34. Bamber J, Cosgrove D, Dietrich CF, Fromageau J, Bojunga J, Calliada F, Cantisani V, et al. EFSUMB guidelines and recommendations on the clinical use of ultrasound elastography. Part 1: Basic principles and technology. Ultraschall Med. 2013;34(2):169-184.

35. Taylor R. Interpretation of the correlation coefficient: a basic review. JDMS. 1990(1):35-39.

36. Huppe D, Zehnter E, Mauss S, Boker K, Lutz T, Racky $\mathrm{S}$, Schmidt W, et al. [Epidemiology of chronic hepatitis $\mathrm{C}$ in Germany - an analysis of 10,326 patients in hepatitis centres and outpatient units]. Z Gastroenterol. 2008;46(1):34-44.

37. Sarrazin C, Zimmermann T, Berg T, Neumann UP, Schirmacher P, Schmidt H, Spengler U, et al. [Prophylaxis, diagnosis and therapy of hepatitis-C-virus (HCV) infection: the German guidelines on the management of HCV infection - AWMF-Register-No.: 021/012]. Z Gastroenterol. 2018;56(7):756-838.

38. Stahmeyer JT, Rossol S, Krauth C. Outcomes, costs and cost-effectiveness of treating hepatitis $\mathrm{C}$ with direct acting antivirals. J Comp Eff Res. 2015;4(3):267-277.

39. Knop V, Hoppe D, Welzel T, Vermehren J, Herrmann E, Vermehren A, Friedrich-Rust M, et al. Regression of fibrosis and portal hypertension in HCV-associated cirrhosis and sustained virologic response after interferon-free antiviral therapy. J Viral Hepat. 2016;23(12):994-1002.

40. Ikarashi Y, Kodama K, Taniai M, Hashimoto E, Tokushige $\mathrm{K}$. The Clinical Difference in the Platelet Counts between Liver Cirrhosis with Nonalcoholic Fatty Liver Disease and Hepatitis C Virus. Intern Med. 2018;57(8):10651070.

41. Karin M, Bevanda M, Babic E, Mimica M, BevandaGlibo D, Volaric M, Bogut A, et al. Correlation between biochemical and histopathological parameters in patients with chronic hepatitis $\mathrm{C}$ treated with pegylated interferon and ribavirin. Psychiatr Danub. 2014;26(Suppl 2):364369.

42. De Ritis F, Coltorti M, Giusti G. An enzymic test for the diagnosis of viral hepatitis; the transaminase serum activities. Clin Chim Acta. 1957;2(1):70-74.

43. Eminler AT, Ayyildiz T, Irak K, Kiyici M, Gurel S, Dolar $\mathrm{E}$, Gulten M, et al. AST/ALT ratio is not useful in predicting the degree of fibrosis in chronic viral hepatitis patients. Eur J Gastroenterol Hepatol. 2015;27(12):13611366. 
44. Thandassery RB, Al Kaabi S, Soofi ME, Mohiuddin SA, John AK, Al Mohannadi M, Al Ejji K, et al. Mean platelet volume, red cell distribution width to platelet count ratio, globulin platelet index, and 16 other indirect noninvasive fibrosis scores: how much do routine blood tests tell about liver fibrosis in chronic hepatitis C? J Clin Gastroenterol. 2016;50(6):518-523.

45. Chen SH, Lai HC, Chiang IP, Su WP, Lin CH, Kao JT, Chuang PH, et al. Changes in liver stiffness measurement using acoustic radiation force impulse elastography after antiviral therapy in patients with chronic hepatitis $\mathrm{C}$. PLoS One. 2018;13(1):e0190455.

46. Holmberg SD, Lu M, Rupp LB, Lamerato LE, Moorman AC, Vijayadeva V, Boscarino JA, et al. Noninvasive serum fibrosis markers for screening and staging chronic hepatitis $\mathrm{C}$ virus patients in a large US cohort. Clin Infect Dis. 2013;57(2):240-246.

47. McPherson S, Hardy T, Dufour JF, Petta S, Romero-Gomez M, Allison M, Oliveira CP, et al. Age as a confounding factor for the accurate non-invasive diagnosis of advanced NAFLD fibrosis. Am J Gastroenterol. 2017;112(5):740751.

48. Paranagua-Vezozzo DC, Andrade A, Mazo DF, Nunes V, Guedes AL, Ragazzo TG, Moutinho R, et al. Concordance of non-invasive mechanical and serum tests for liver fibrosis evaluation in chronic hepatitis C. World J Hepatol. 2017;9(8):436-442.

49. Li SM, Li GX, Fu DM, Wang Y, Dang LQ. Liver fibrosis evaluation by ARFI and APRI in chronic hepatitis C. World J Gastroenterol. 2014;20(28):9528-9533. 